Article

\title{
Analysis of BIM Methodology Applied to Practical Cases in the Preservation of Heritage Buildings
}

\author{
Alcinia Zita Sampaio ${ }^{1} \mathbb{D}$, Augusto Martins Gomes ${ }^{1}$, Alberto Sánchez-Lite ${ }^{2, * \mathbb{D}}$, Patricia Zulueta ${ }^{2}$ \\ and Cristina González-Gaya ${ }^{3}$ (D)
}

1 Department of Civil Engineering, Architecture and Georesources, Instituto Superior Técnico, Universidade de Lisboa, Avenida Rovisco Pais, 1049-001 Lisboa, Portugal; zita.sampaio@tecnico.ulisboa.pt (A.Z.S.); augusto.gomes@tecnico.ulisboa.pt (A.M.G.)

2 Department of Materials Science and Metallurgical Engineering, Graphic Expression in Engineering, Cartographic Engineering, Geodesy and Photogrammetry, Mechanical Engineering and Manufacturing Engineering, School of Industrial Engineering, Universidad de Valladolid, Paseo del Cauce 59, 47011 Valladolid, Spain; pzulueta@eii.uva.es

3 Department of Construction and Manufacturing Engineering, ETSII-Universidad Nacional de Educación a Distancia (UNED), C/Juan del Rosal 12, 28040 Madrid, Spain; cggaya@ind.uned.es

* Correspondence: asanchez@eii.uva.es

Citation: Sampaio, A.Z.; Gomes, A.M.; Sánchez-Lite, A.; Zulueta, P.; González-Gaya, C. Analysis of BIM Methodology Applied to Practical Cases in the Preservation of Heritage Buildings. Sustainability 2021, 13, 3129. https://doi.org/10.3390/ su13063129

Academic Editor: Antonio Caggiano

Received: 25 January 2021

Accepted: 11 March 2021

Published: 12 March 2021

Publisher's Note: MDPI stays neutral with regard to jurisdictional claims in published maps and institutional affiliations.

Copyright: (c) 2021 by the authors. Licensee MDPI, Basel, Switzerland. This article is an open access article distributed under the terms and conditions of the Creative Commons Attribution (CC BY) license (https:// creativecommons.org/licenses/by/ $4.0 /)$.

\begin{abstract}
The methodology and technology associated with building information modeling (BIM) provide architects, engineers, and historians with concepts and tools that support the development of heritage projects. However, this specific form of BIM orientated towards buildings of patrimonial value — known as historic building information modeling (HBIM) - requires a distinct and additional view, accounting for aspects which are normally not attended to on projects involving new buildings. In an HBIM context, the parametric modeling process, the basis of any BIM procedure, involves the study of shapes, patterns, or standards for the establishment of particular collections of parametric objects, as well as the record of the available technology used to capture digital geometric data. In addition, all the information collected and generated through an HBIM process must be adequately managed, maintained, and archived. In the present study, we intend to list the most recent features of HBIM, based on a bibliographic review, encompassing distinct building situations (preservation, restoration, rehabilitation, and structural assessment); different technical equipment (drones, scanners, and photogrammetry); as well as diverse forms of geometric characterization (patterns, geometric rules, or curve generation) and ways of archiving data (stratigraphy, old drawings folders, or as-built models). With the aim of identifying, as an overview, we have presented the principal modeling strategies, technologic devices, and archive procedures, as a contribution to systematizing and organizing the dispersed practical and theorical studies related with HBIM.
\end{abstract}

Keywords: BIM; building preservation; documentation collecting; geometric standardization; HBIM; parametric modeling

\section{Introduction}

The concept of building information modeling (BIM) considers the generation, updating and reuse of information, centered on a three-dimensional (3D) model, forming a basis for the development of collaborative projects and allowing the participation of all stakeholders. The principal foundation of the generation of a BIM digital model, is the modeling process itself, which is based on the use of parametric objects [1]. In the context of modeling buildings of historic value with particular architectural configurations, the rigorous representation of all building components and ornaments, both in their geometric aspects and physical properties associated with the materials applied, have been considered important topics in relation to the most recent area of BIM, namely, heritage building information modeling (HBIM) [2-4]. The HBIM concept is a current topic of investigation 
and application in real cases oriented towards the preservation or refurbishing of old buildings with a historic or heritage value, based on the BIM methodology. Focusing mainly on the Web of Science ${ }^{\mathrm{TM}}$ Core Collection, more than 112,200 publications can be found on the subject of building information modeling (BIM) up to the year 2021. A content analysis of titles and abstracts of all 112,200 BIM publications can be conducted, and 159 publications related to HBIM can be identified using "HBIM", "heritage" and "historic building" terms. With these 159 HBIM publications, the "practical case" term can be used to identify 59 publications on HBIM applications (31 articles and 28 proceedings papers, all published in English) from 2017 to 2021. Of those 59 publications, real historical building cases with clearer methodological background of HBIM can be selected.

When modeling a new building, BIM-based systems provide parametric objects of generic shapes, sorted by family type, which are easily adaptable to each specific case. In relation to old buildings, the current libraries of objects are very limiting. Using only the available libraries of object of building components makes it difficult to achieve a satisfactory representation of heritage architecture. However, to support the correct analysis of all aspects concerning old buildings, rigorous modeling of the architectural geometry and knowledge about the traditional constructive solutions adopted are mandatory. Thus, in order to achieve a correct approach to the representation of the exact architectural configuration characteristics in each epoch, the establishment of appropriate parametric objects is needed.

The history of the construction practice of a building that has gone through several architectural trends and followed the evolution of the construction solutions applied must be first collected and studied. Then, all this information must be archived, comprising the basic documentation necessary to adequately support to the development of projects, whether for the purpose of preserving, repairing or rehabilitating old buildings [5]. As such, the conservation of buildings of architectural heritage value involves a process of knowledge, maintenance, management and enhancement aimed at preserving data relating to complex systems, such as heritage buildings, which are the result of historical events, different architectural influences, changes in ownership, and transformations over time [6]. According to Bruno and Roncella [7], an HBIM model—composed of parametric objects and associated with distinct types of information such as old drawings, inspection reports and alternative refurbishment solutions-heightens the ability of researchers to archive and organize the information available about an old building, and therefore HBIM is currently considered a promising resource for the planned conservation of historical assets. HBIM is useful for the digitization of cultural heritage, which involves surveying historical data and the generation of geometric models, with the advantage of integrating fragmented domains such as architecture, engineering or facility management, and the different data types used by distinct experts involved in heritage studies [8].

Keeping alive the remnants of history and respecting the past and the value acquired over years or centuries is essential. It is not just the use of the building that imposes degradation requiring conservation studies, but also natural catastrophes such as earthquakes, seaquakes or floods, which impose serious problems on the reconstruction process and on the safeguarding of buildings' historical or heritage value. In fact, the availability of information concerning historical buildings is complex and limited, frequently leading to the establishment of inadequate processes of recovery. As such, collecting and archiving data in a centralized BIM platform is a great support to professionals involved in developing preservation works.

The present study is limited mainly to practical case and intends not only to introduce the HBIM concept, but also to describe the main aspects that are currently the targets of research within the HBIM sphere, contributing to its dissemination and its application in this particular sector of the construction industry. The main objective of our study is to transmit, essentially, practical knowledge. A rigorous modeling component is required, and several techniques for collecting data are available to support this. After all, the information collected and created must be associated to the model. Standardizing old architectural 
forms and archiving the relevant documentation are the fundamental premises that we intend to explore in this study.

\section{Standardization and Modeling}

The recently proposed HBIM concept involves stages of collecting and processing images, identifying historic details in pattern books and creating new collections of modeling objects. The establishment of specific parametric objects that are representative of the architectural elements and the range of ornaments commonly presented in heritage buildings is difficult, as these are usually not typed, and they are unique in each case. With the aim of identifying characteristic patterns of distinct epochs and in support of the generation of particular collections of objects, an analysis based on the interpretation of architectural manuscripts ranging from Vitruvius (1st century BC) and Palladio (1508-1580) to the books of antique architecture recording geometric details from the 17th and 18th centuries must be first performed (Figure 1):

- The roman author, Marco Vitruvio, was responsible for the oldest manuscript on architecture, and was the founder of the modern understanding of architecture and construction, having established rules of aesthetic proportion.

- The Italian architect Andrea Palladio published, in 1570, a work in four volumes, which became fundamental in the history of architecture, as it addressed architectural orders, public buildings and sacred construction.

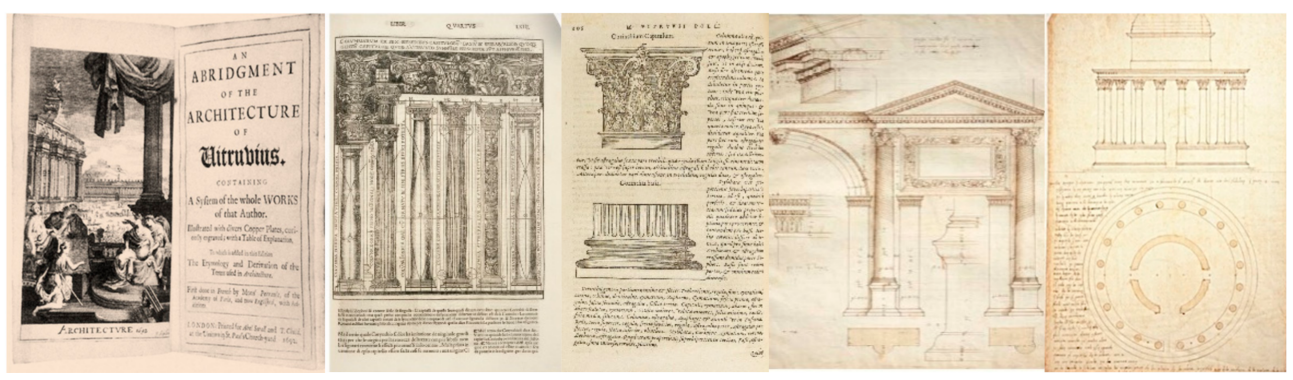

Figure 1. Illustrations of Vitruvius and Palladio manuscripts.

The rigorous modeling process in an HBIM project requires a sustained study of art history. Not just in Europe but also in other continents, HBIM has been introduced. However, in Malaysia, Maisarah et al. [8] reported that the adoption of HBIM within the construction industry has been slow because of a gap in the modeling skills of the professionals and the need to involving different experts in a collaborative approach. Therefore, the first stage of HBIM was carried out based on the literature, followed by training in the use of BIM tools and the establishment of integrated new procedures, in order to provide a better understanding in the handling of historical buildings, as well as allowing enhanced communication and documentation. Cheng at al. [9] reported that the refurbished engineering of historic buildings in Taiwan has been supported by the contribution of HBIM and it has introduced a great challenge for conservation heritage, not only in the reconstruction of damaged areas but also in restoring tangible cultural heritage works.

\subsection{Standardization Rules}

According to Murphy et al. [3], the HBIM concept is an innovative direction of BIM in which interactivity with the parametric object must allow the architectural elements to be properly represented, both in geometry and in the constituent material. In order to improve the framework for the digital 3D modeling, a major challenge is to obtain the suitability of the BIM platform for historical architecture. A specific trial in HBIM guarantees an appropriate level of geometrical accuracy and contributes to demonstrating the feasibility of HBIM implementation for complex architectural shapes. 
Commonly used BIM-based systems contain a wide range of parametric elements that are already in the internal library of tools that can be immediately applied. However, concerning the modeling of old buildings, the user normally needs to generate specific objects, which can be created as collections of objects outside the system, or which can be imported into the model from other projects or even found in libraries that are available for free in on-line databases. However, the parametric objects that are created specifically for a particular house for the representation of details and ornaments compose an individual library of elements. In HBIM, studies concerning the collection of information and the characterization of rules for the generation of shapes aim at the establishment of libraries of objects sorted by epoch and type of construction, be it aristocratic, religious or institutional, to be reused in houses of similar architecture [2].

The construction of a parametric library of architectural elements requires the detailed study of construction techniques, which can be supported by manuscripts on architecture, framed to each epoch. The historical evolution of these manuscripts, following a chronological order, allows the identification of characteristic rules of ornaments applied in classical buildings of heritage value, which should be able to be represented in computational modeling, through specific collections of parametric objects. Figure 2 illustrates the generation of a particular family of windows using the modeling capacity of the tool used to define new object collections. The parametric object was added to an HBIM window library [9].

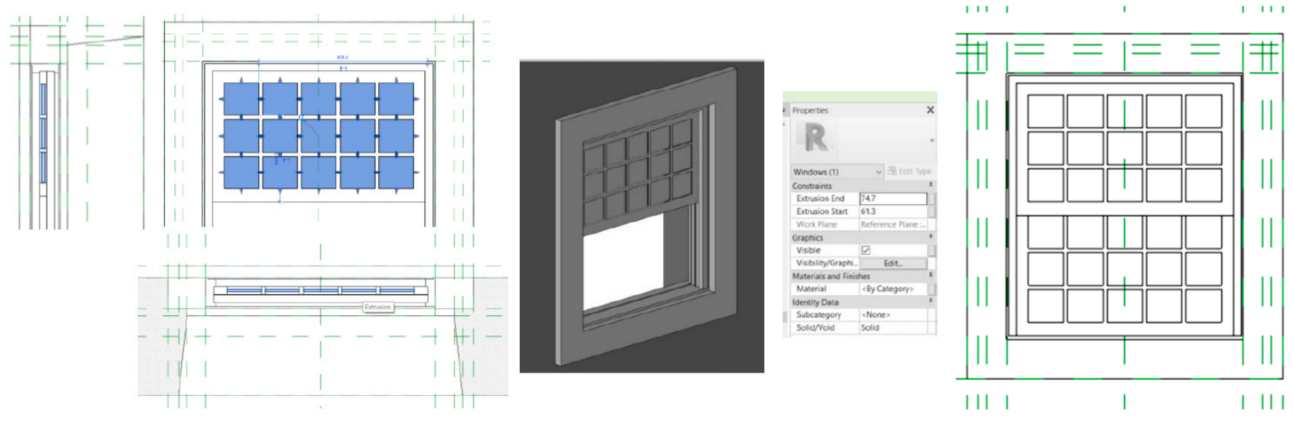

Figure 2. Generation of a specific type of windows present in a building of patrimonial value in Lisbon [9].

In BIM models, the parametric objects used in the modeling process and the associated attributes that were considered in each case follow a data hierarchy and semantic organization. This is a fundamental and central aspect of the available BIM software, as it allows the sharing of the multiple data inserted in the model. This enriched and organized model offers several advantages in obtaining directly two-dimensional drawings and in the management of a large amount of data concerning distinct architectural shapes. Therefore, the collection of data pertaining to all significant aspects and the ability to archive these in a 3D format may allow HBIM to become the preferred mode of managing the process from survey to restoration.

The pattern shapes applied in old buildings usually follows rules with definitions that are properly documented and illustrated. In an HBIM study by Pinto [9], in order to respect the architectural history, several elements were generated using basic geometric forms like oval and circular geometries and cylinders, as shown in Figure 3.

Thus, it is relatively easy to identify the generation of forms of revolution based on arcs or other specific curves, supporting the characterization of new parametric objects, thereby creating specific libraries of collections of objects:

- Components of Doric, Ionic or Corinthian Greek orders of columns, such as base, shaft, capital and abacus and proper details, namely, the echinus and fluting parts;

- Romanesque portals with suitable details in pedestal, jamb or archivolts or Gothic ceilings with the intersection of cylindrical or spherical configurations. 

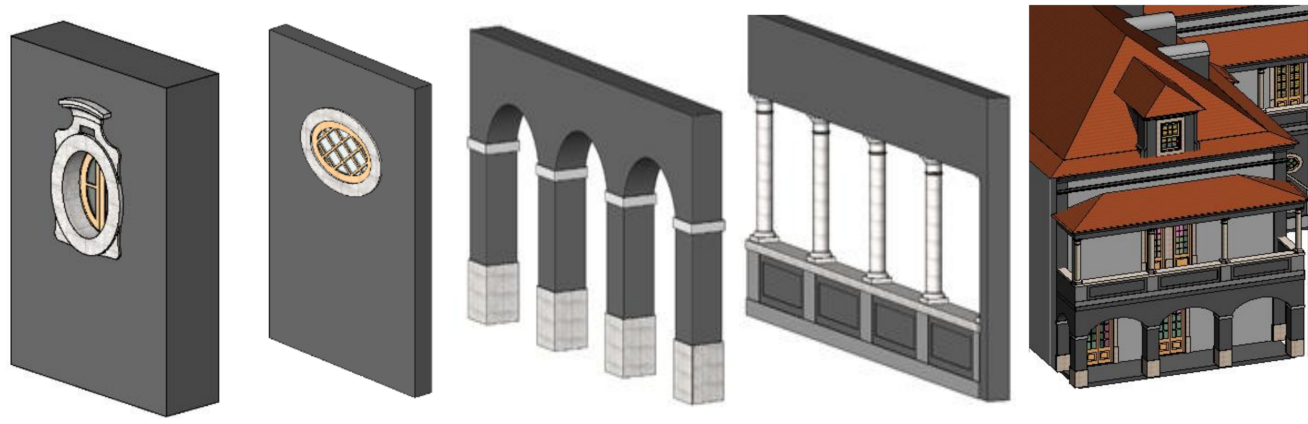

Figure 3. Oval windows, circular forms in openings and cylindrical columns in a balcony [9].

Osello et al. [6] presented a reconversion study for the hotel use of a building of historic value in Turin, Italy, using BIM modeling standardized forms, established on the basis of the collection of documentary data and on a local visual inspection. The consulted archival documents stated that its construction dated to the 19th century. However, on the mid-18th century, important rehabilitation work took place, requiring the renovation of the interior space, the reinforcement of the construction system and the restoration of some decorative details.

The proposed reconversion project was supported by the HBIM methodology. First, the collection of the available information was made, and then the characterization of the traditional construction process of the building was carried out, allowing the identification of the mode of construction used and the material composition and proprieties of all building components. Based on the collected information, a rigorous HBIM model was created. The parametric objects used in the model were adapted from generic collections of objects available in the system and other objects were specifically generated and used.

The interpretation and understanding of geometric rules are fundamental to the transposition, in parametric terms, of the books of architectural patterns to the HBIM modeling process. Classical architecture is based on components of regular geometric proportion and a limited range of materials and textures, which is particularly interesting in order to identify regular geometries that can be directly used to generate parametric objects with realistic geometry and physical properties of materials. The images included in Figure 4 refer to the main façade of a building of patrimonial value located in Lisbon [9], presenting ornaments made of stones. For its modeling, the identification of patterns was required. For the interior of the house, the floors made of wood were modeled using objects available in the library of BIM tools. The HBIM final product should be a complete 3D geometric model, including rigorous geometric detailing, the identification of the materials used at the time and the recognition of the construction solutions applied. In this case, the materials associated with objects were stone and wood [9].
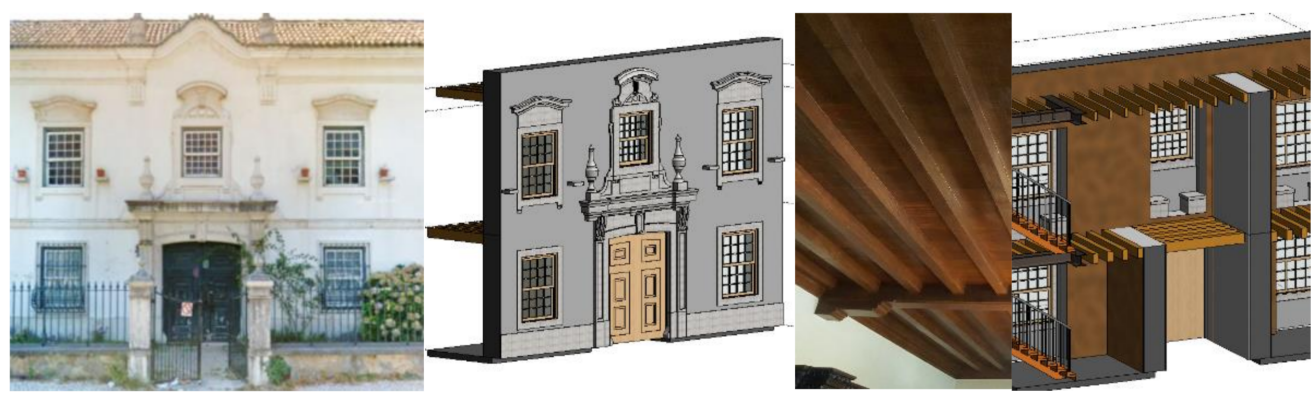

Figure 4. Identification of patterns in a façade and current objects used on the floor model [9].

\subsection{Generation of Specific Collections of Objects}

The translation of the complexity of historical construction into a 3D model, using tools that incorporate rigid regulatory algorithms-a characteristic underlying the parametric 
modeling of available computational instruments-constitutes a limitation to obtaining a reproduction of reality, which contrasts with the variability and specificities of the historic construction.

Ramalho [10] performed an analysis of the degree of degradation of the sculptural and decorative elements that make up the main portal of the Cathedral of Oporto, Portugal. The configuration of the decorative elements is representative of religious construction from the beginning of the 12th century. The geometry presented in the church was analyzed with the objective of studying the regular patterns, in order to identify its exact geometry, defined as rules of analytical geometry referring to circular and elliptical arcs and parametric curves of evolution. In this sense, BIM modeling systems showed a sufficient ability to represent them in a way that was identical to computational systems of drawing tracing.

Additionally, the study of basic geometric forms on a theoretical basis, known as the grammar of forms, introduced in the 1870s, is a concept that allows the analysis of geometry and its representation in terms of computational modeling. The grammar of forms concept refers to a research perspective that looks to standard geometries in order to produce specific libraries of parametric objects. Following Cenani [11], grammars of forms or shape grammars are the algorithmic systems used to analyze existing designs or create new ones. The architecture of old buildings is based on the inter-connection of architectural styles, which can be subdivided and represented by sets of basic shapes, which are ruled by geometric transformations of regular or parametric curve generations. In Malaysian architecture, examples were also found of composed forms, and according to Ali, Maisarah et al. [8], HBIM permits better understanding about a component's nature in terms of its element and sub-elements, as it allows the practitioner to deconstruct and reassemble historical components for a better understanding of their nature (Figure 5).
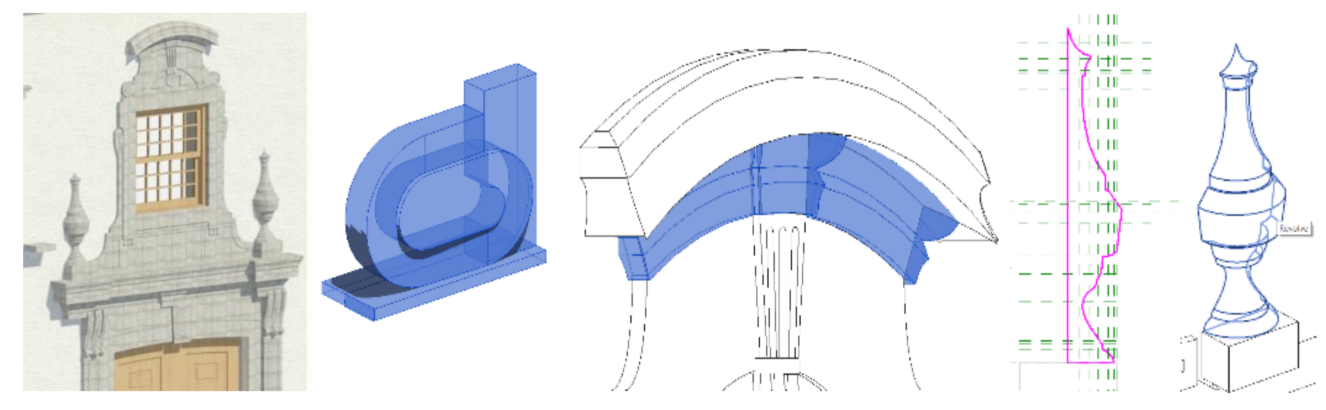

Figure 5. Generation of specific collections of ornaments based on the decomposition of forms [10].

In the study of a housing conversion proposed by Pinto [9], referring to a palace from the beginning of the 20th century, located in Lisbon, a library of specific collections of objects was created and applied in the rigorous process of modeling. The building of patrimonial value has identical characteristics to other buildings in the city of Lisbon, which mark the aristocratic construction at the time. As the library of the software used did not allow the strict representation of particular details presented in the house's facades, the authors used the ability of the system to generate collections of objects in order to define a set of specific objects. The identification of generative rules of forms allows for the automatic generation of configurations of distinct architectural styles, and its direct application in the generation of HBIM collections of objects. Murphy et al. [3] identified several specific collections of objects, which were individualized by historical age and by type of construction. In the study of a palace, basic generative forms were also identified (Figure 5).

The modeling process in relation to windows and doors requires relevant modeling and is time consuming (Figure 6). In addition, the BIM tool used acquires the archive of the generated collections of objects, establishing a reusable HBIM library to be applied in the modeling of buildings of identical typology. 

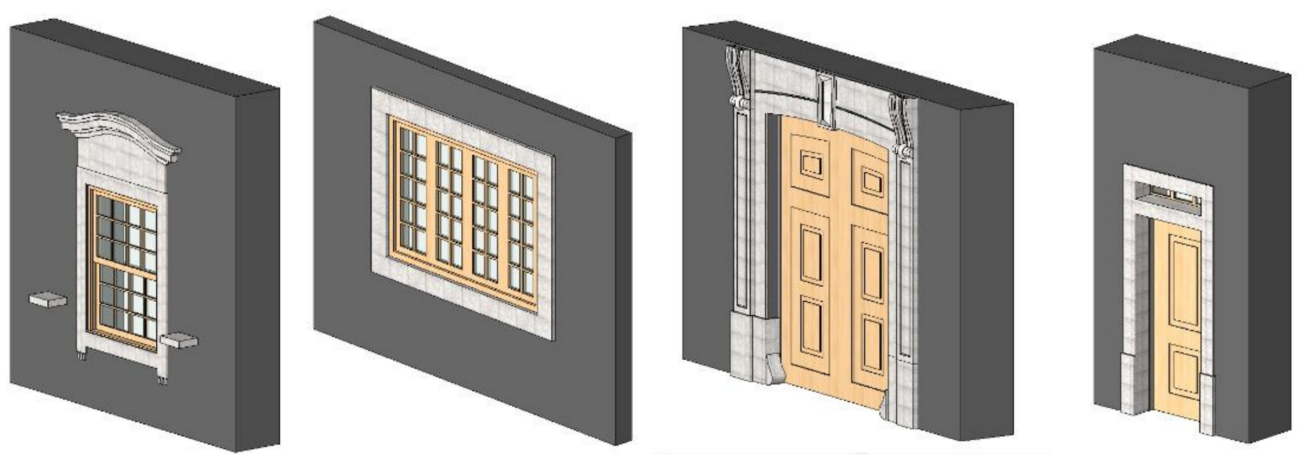

Figure 6. Generation of a historic building information modeling (HBIM) library of windows and doors [10].

In relation to the reconstruction process of the Basilica di Collemaggio, damaged by the earthquake that occurred in L'Aquilla, Italy, in 2009, Brumana [4] considered the HBIM methodology. The columns, in stone masonry, were strongly affected and some stone volume was lost in each block that made up the layers of the vertical elements. It was necessary to perform the correct modeling of each column and the identification of the degree of the loss of stone as a percentage of the amount of material that would need to be replaced. The shape detail of the masonry columns was defined at the scale of the stone block, and a distinct color was used to represent the severity of the observed damage in loco. Performing the illustrative visualization required each level of stone in a column to be individualized within the set of stone pieces of which it was composed, and to each one a parameter identifying percentage and color was assigned. This meticulous work was made possible by the use of BIM modeling parametric tools-in this case supporting, in a first visual phase of analyses, the verified damage to the basilica. The reconstruction work and the replacement of the stone were analyzed in relation to the generated HBIM model, with the necessary information incorporated in it.

\section{Documentation and Digital Data}

Concerning historical or heritage buildings, modeling and visualization BIM tools are used un the collecting, management, maintenance and archiving of data needed to support strategies of conserving architectural value and traditional construction processes. This type of study requires interdisciplinary teams to develop their activity in a collaborative way over a common work platform. In the development of an HBIM project, a great level of rigor should be imposed on the geometric modeling process, but great care is also required in order to support the incorporation of data relating to materials and constructive techniques used or the assessment of the state of conservation. The available data are of different natures, such as texts, documents captured by scanners or digital photographs, sketched documents and old drawings. Saving information in a centralized and easily accessible model is a very useful tool in the management of historical heritage, providing the documentary basis for the analysis and development of preservation projects.

\subsection{Registered Documents}

The strategy for the conservation of private or industrial heritage is often directed to remodeling of an interior space, while preserving its identity. The information recorded in registered documents of the historical building normally provides relevant data regarding the characterization of the construction (historical epoch and construction systems) and the description of the interventions carried out through time. The management of architectural heritage using digital technologies makes the process of saving documents, as well as its maintenance and updating, more agile, complete and accessible, providing an important benefit in the preservation of old buildings. The archiving of all data available allows researchers to structure a building's documentation, consisting of the information collected and created, thus supporting studies for future interventions. 
The study of a structural rehabilitation in a building located in a noble area of the city of Lisbon, proposed by Pinto [9], began with a documentary collection requested from the Municipal Archive of Lisbon. The consulted documents were composed of drawings of plants, elevations and cross-sections, dated 1924, and other drawings presenting the changes made (indicated in yellow and red) up to the year 1953 (Figure 7). In order to generate the parametric objects representative of windows and doors, a sketching survey composed of a large set of drawings and a detailed photographical study was carried out on-site.

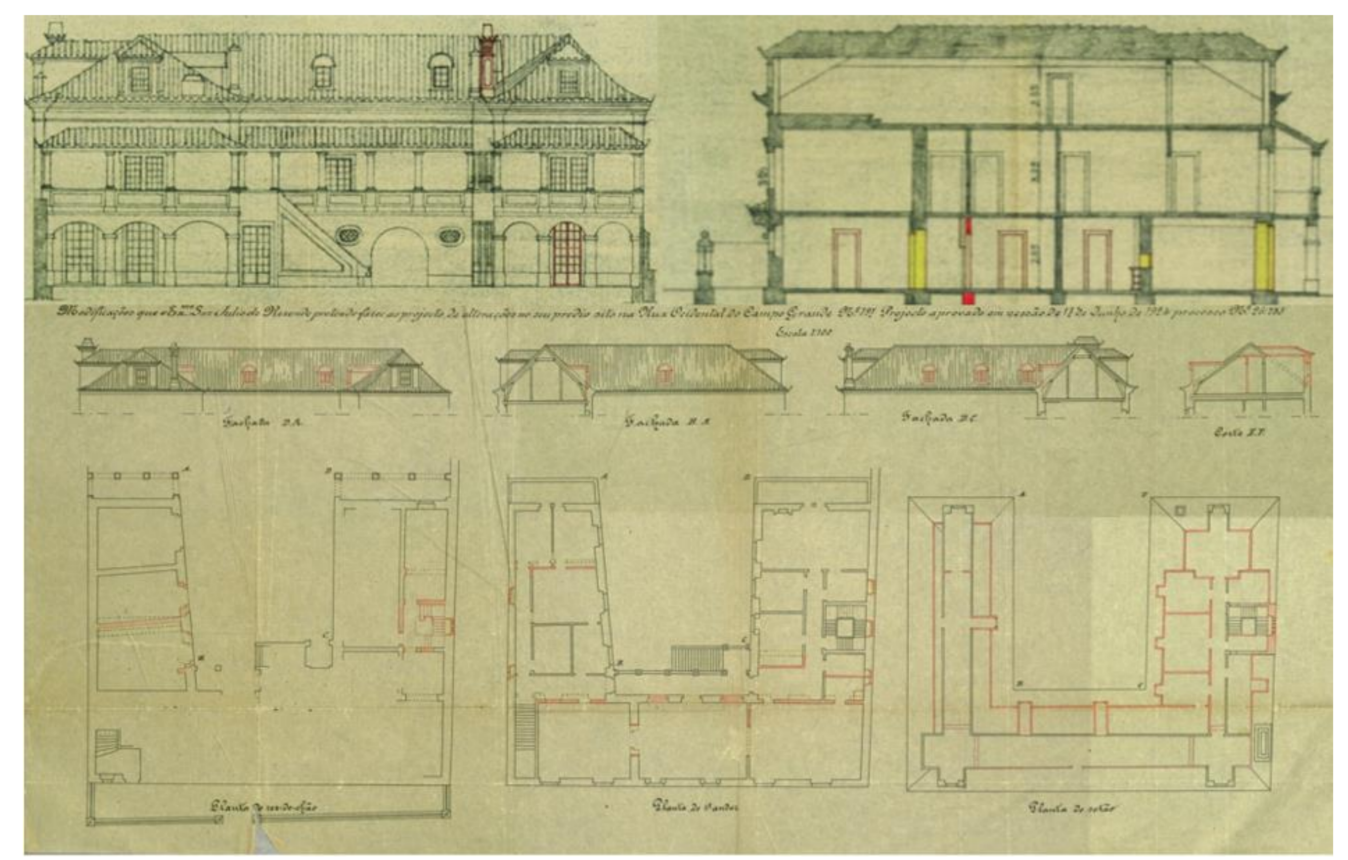

Figure 7. Archived graphical documents concerning an aristocratic house in Lisbon [9].

In addition, an inspection was made in loco concerning the evaluation of the state of conservation of the building components, oriented towards the structural elements and the coatings of floors and walls (Figure 8).

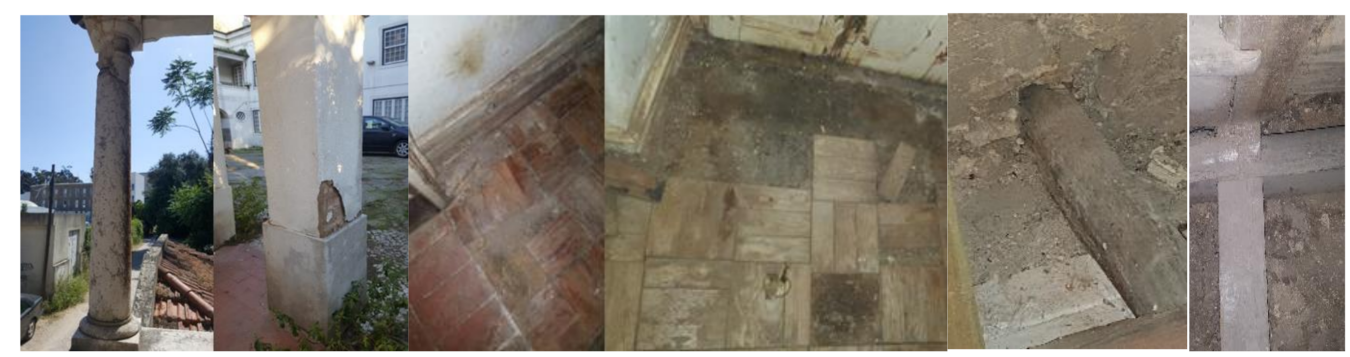

Figure 8. Set of photographs presenting anomalies verified in construction components [9].

In the context of the reconversion project of the old flour factory, La Julita, in Valladolid, Spain, in a research center, Sanchez et al. [12] carried out an initial documentary survey. Old drawings of the factory were found in a publication by Carrera [13], dated 1865. The drawings were composed of elevations, plants and vertical cuts, allowing the authors to understand the initial structural composition of the main building, which consists of four floors and a sloped roof. The graphical documentation survey was complemented by photographs obtained on site, and by an analysis of the state of ruin found there. It was then possible to perform the modeling of the building and to study the current state of conservation of the building. 
Based on the collected data, a proposal for the rehabilitation project was performed and the respective BIM model was generated. The window and door elements were adapted from the basic library of the BIM system used, but the representation of all the factory equipment, composed of machinery and the supporting construction elements, required a specific modeling process that led to the generation of collections of particular parametric objects, which was time-consuming. Several as-built models were generated, presenting the original ones, based on old drawings, and the current state, based on a photographic survey and a local inspection and the project proposed (Figure 9).
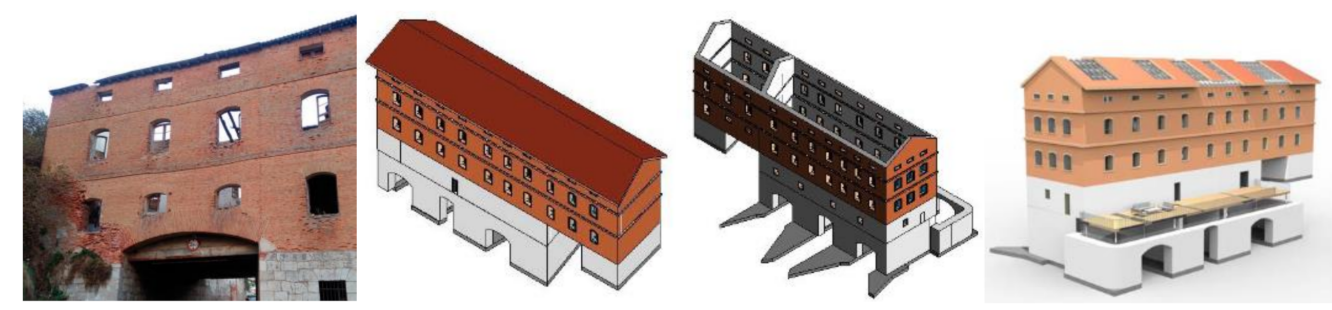

Figure 9. Photograph of the ruined building and several as-built building information modeling (BIM) models [12].

As a prerequisite for the development of a proposal for the restoration of the Bom Jesus Church, in Minas Gerais, Brazil, Tolentino [14] carried out a cadastral survey of the existing documentation, together with the National Institute of Historical and Artistic Heritage, consisting of drawings of plants, the roof, facades and vertical cuts. In addition, a photographic survey and damage mapping were carried out, with the objective of analyzing the current state of conservation of the building, which formed the basis for the creation of an HBIM model. The principal purpose of the study was to collect all existing documentation, involving its updating and reorganization, and archiving it in a digital way, in order to contribute to the documentary preservation of the church.

\subsection{Photogrammetry and Stratigraphy}

A study by Murphy et al. [3] describes the use of laser scanner and photogrammetry techniques to survey architectural elements from the perspective of identifying rules to be used in the design of parametric objects. The photogrammetric survey consisted of obtaining photographs from distinct points of view. Then, removal algorithms of perspective effects were applied over those projections and they were adjusted to an adequate scale to allow for correct dimensioning. Under HBIM, this process is used to achieve a high level of geometric detail of the buildings' components and decorative elements, in order to allow rigorous parametric object generation.

A historical monument is usually characterized by the overlapping of construction interventions carried out in remodeling interventions, which take place over time. These previous works are noted by the presence of different materials or architectural historical remarks. A stratigraphic analysis covers the study of constructive and destructive actions in a building. The field of stratigraphy by specialists dealing with cultural heritage should be a necessary scientific complement to the collection of the history of a building's construction [15]. In restoration activities, stratigraphic procedures are applied in the analysis of painting on walls. The constructive steps are represented by different colors, leading to a visual perception of the constructive chronology, supporting the analysis of the architectural solutions applied. The representation of stratigraphic analysis has been applied in photography and drawings. For this, an analysis of the building process is required, namely, the identification and numbering of all the stratigraphic units and their association with the respective historical periods [16,17].

In HBIM, the collections of objects that make up the digital model can be associated with parameters related to distinct periods of historical time and constructive remodeling works, which can be presented with different colors in the model. In relation to the National 
Palace of Sintra [18], a historical documentary analysis was carried out, which was applied to the created BIM model, illustrating the different remodeling interventions, from the Arab period, through the kingdom of D. Dinis to D. Manuel I and the 17th century.

\subsection{Laser and Drone Technologies}

3D laser scanner technology detects, with a high precision and with a rapid acquisition rate (millions of points per second), the configuration of facades and interior walls, in the form of a cloud of points, associated with coordinates $(x, y, z)$ and with color intensity (red, green and blue, RGB). The earth device, based on 3D scanner technology, explores the use of laser light in obtaining the distance between the equipment and the surface of the object, through the measurement of time of emission, reflection and return of an electromagnetic wave of light. In an HBIM process it is necessary to establish a station of laser devices, properly positioned, so that the 3D points obtained can be unified in a unique cloud of 3D points. The configuration is then identified using surface shape recognition algorithms, essentially based on the Geometric Description Language (GDL) and later converted into parametric objects.

In order to perform a complete and adequate seismic assessment of the National Palace of Sintra in Portugal, a complex structure composed of different unreinforced masonry buildings, a multidisciplinary expertise collaboration was undertaken. A 3D architectural model of the monument was created based on a laser-scanning survey, complementing prior graphical and a photographic surveys. A 3D scanning detection campaign was established, with laser device stations located inside and outside the building [16].

Cheng et al. [19], in a refurbishment case in Taipei, Taiwan, used laser scanning and photogrammetry for the recording of cultural heritage sites. These technologies have made it possible to efficiently and accurately record complex structures remotely, which would not have been possible with previous survey methods. In addition to these developments, digital information systems are evolving for the presentation, analysis and archival of heritage documentation. Using the St-Pierre-le-Jeune Church, Strasbourg, France as a case study, Yang et al. [20] refer to an ontology model concept using built-in visual programming to develop a mesh-to-HBIM process approach that allows them to segment the surface mesh of an architectural geometry capture by lasers and transfers the primitives to BIM elements. Previtali shows other example in Magio Palace, Cremona (Italy), integrated photogrammetry and laser scanning technologies [21].

A laser device station was also used in the Giulio Romano [22] architectural recovery project in Mantua, Italy, where the HBIM approach was adopted, covering the design and planning phases of the restoration work. BIM modeling tools supported the importing of clouds of 3D points, allowing the accurate representation of the building components, including masonry walls, columns, arches and vaults. As complementary information, photographs were obtained, new inspections were carried out and the constructive techniques applied at the time were studied.

However, the process of identifying parametric objects is complex and time-consuming. The details of the main façade of the market included the modeling of the metal elements, named insects, used to join the stone elements of the columns-a technique used by the architect Giulio Romano (1492-1546). HBIM modeling involved the generation of all components created as a composition of parts, associated with distinct materials and presenting different states of degradation and historical phases. Furthermore, in L'Aquila, as reported by Brumana et al. [4], after the earthquake that occurred in 2009 the different actors involved in the preservation process worked through an HBIM environment, and as a first step, laser-scanner and photogrammetric surveying was performed in order to make decisions about alternative solutions. The case study "Nasif Historical House", which lacked previous engineering data, is another good example in which a building's main body was modeled based on combinations of laser scans generating a 3D point cloud [23]. In the practical case of the orthodox cathedral of Nicosia, researchers focused their methodology on the implementation of a database that described the characteristics of the architectural 
components from a historical perspective, integrating several techniques (photogrammetry, laser scanning) for 3D acquisition [24].

Regarding the work of Tolentino [14], a laser scanning survey was also carried out, "and a set of 46 scenes was obtained in approximately $10 \mathrm{~h}$ of fieldwork". The BIM building model was developed, based on a cloud of 3D points. Using the library of generic objects, available in the modeling software, the floors, walls and roof were modeled, and, making use of editing capacity of the software, several specific collections of windows and doors were also generated.

\subsection{Concept of Information Hierarchy}

One of the most innovative aspects of the HBIM concept is the so-called as-built model, in which the BIM model is created in order to incorporate parameters with different types of information, organized by historical stages of construction, and archived as layers of duly dated data, forming a hierarchical and chronological sequence of information. The aim of the BIM model composed of various information "ages" is to promote the conservation and updating of heterogeneous information related to old buildings.

The 10th century Church of Santiago de Peñalva [25], located in Castilla y León, Spain, of Mozarabic-Hispanic architecture, was registered in 1931 in the Dirección General de Patrimonio Cultural as a National Historical-Artistic Monument [26]. This entity requested a research work oriented towards an innovative reorganization of digital information, in order to complement the existing registered documentation, encompassing the historical and artistic contextualization of the monument. The documentation, organized according to the hierarchy of the as-built model and in a digital format, was made accessible to experts when developing preservation, restoration or recovering works.

The BIM as-built model of the church, structured according to the chronological evolution of the building construction, was created based on the data collected. The information referred to the documentation available in the national archives, as well as a graphical survey made of sketches associated with dimensions, a set of photographs and data from a 3D laser scanner process performed inside and outside of the building. In addition, a local inspection assessing the real state of degradation and conservation of walls, columns, floors and roofs and decorative elements of the building was performed. The data, inserted in a BIM model, can be filtered according to specific parameters related to distinct constructive epochs, as a basis for the analysis of studies of preservation, restoration or as a support to the management of the monument itself.

\section{Results and Discussion}

A quantitative analysis was performed, using co-occurrence maps based on text data from 59 publications from the Web of Science database concerning practical cases of HBIM techniques. These maps were developed using VOSviewer software [27]. Titles and abstracts of all these publications included 2028 different terms. With a threshold of a minimum number of occurrences of three for each item (this means that the item was found in at least three publications), 182 terms could be selected. A relevance score was calculated, and 28 of these items were selected as the most relevant items. Based on a clustering technique, these items were divided into three clusters. Figure 10 shows the cluster density map, the item density map and the network visualization map.

In the network visualization map, items are represented by their label and by a circle. The size of the label and the circle of an item is determined by the occurrence of the item. The higher the occurrence of an item, the larger the label and the circle of the item. The color of an item is determined by the cluster to which the item belongs. Lines between items represent links. The distance between two items approximately indicates the relatedness of the items in terms of co-occurrence links. In general, the closer two items are located to each other, the stronger their relatedness. The color of an item in the cluster density map is determined by the cluster to which the item belongs. Each point in the density map has a color that depends on the density of items at that point. A warm color means a 
higher number of items in the neighborhood of a point and a higher co-occurrence of the neighboring items.

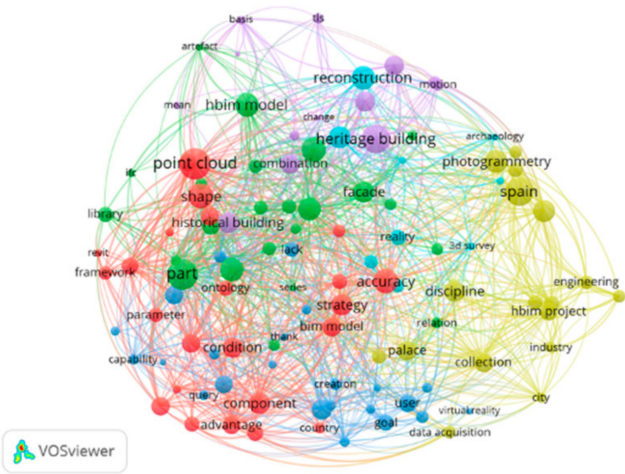

(a)

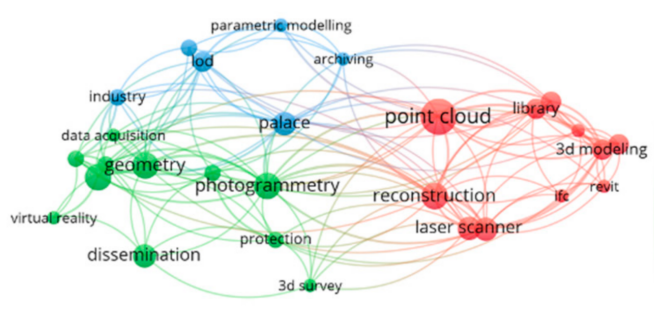

象 vosviewer (c)

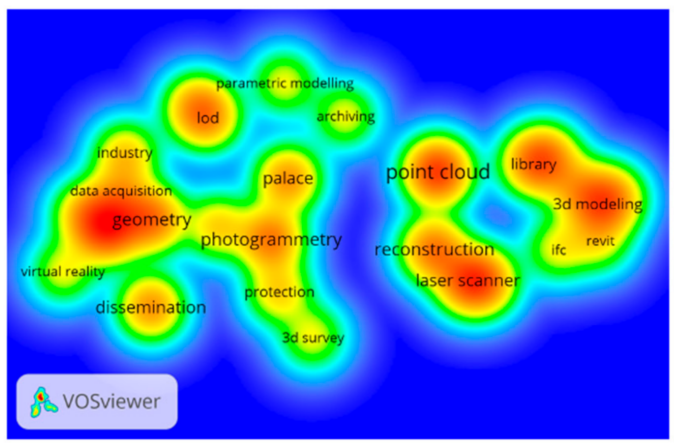

(b)

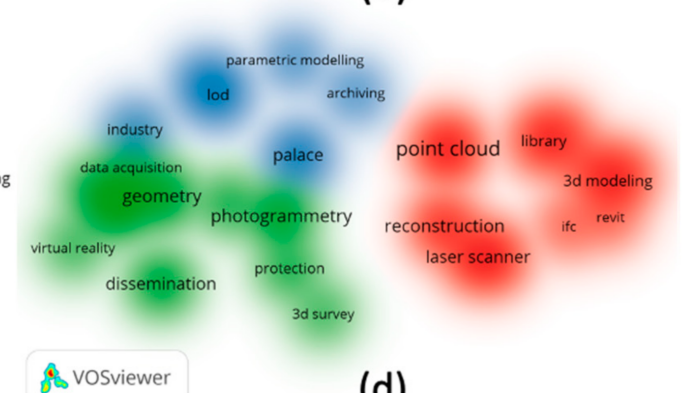

(d)

Figure 10. (a) Network visualization map (182 terms); (b) item density map (28 terms); (c) network visualization map (28 terms); (d) cluster density map (28 terms).

Items with a high occurrence and co-occurrence were reconstruction, preservation, photogrammetry dissemination, geometry, parametric modeling, laser scanner, linked open data (lod), virtual reality, archiving, point cloud, protection, industry, and palace.

In recent HBIM studies, the main analyzed issues were essentially related to:

- The methodology of collecting information based on the existing documentation, on local graphic appointments and photographic surveys and on the use of digital imaging capture equipment (laser scanners and drones).

- The attempt to standardize architectural configurations, with the intention of creating specific parametric objects representative of details presented in old buildings.

- The analysis of constructive techniques used, with the objective of preserving knowledge of the methodological technology and identifying the physical properties of the applied materials.

- The archiving of old documents (drawings and written reports), previous interventions that were eventually carried out through time and making the information availability for consultation by professionals involved in the development of future intervention projects.

Recent educational studies and practical reports have explored the implementation of BIM technology in historical environments, supporting the digital preservation of the information collected and the visualization of digital 3D models enriched with the available related information. In order to adequately support the elaboration of restoring or recovering proposals for old buildings, a previous study of the old building should be performed as follows: 
- The HBIM domain encompasses the initial process of studying the historical contextualization of the building, the mastery of traditional technologies and materials applied in the old construction and the archive and management of all information collected and created.

- A first collection of data must be made, focused on the analysis of the different construction stages of the building, on the registered documentation found in national or city archives and on local inspection of the building in order to assess the current state of conservation (abandon, ruin or degradation).

- A building of patrimonial value usually admits a history of transformations made over time, motivated by different architectural influences and by the change imposed by housing reconversion required by successive owners.

- Any rehabilitation project to be proposed must strictly respect the past and historical value acquired over the centuries and, supporting that, a multidisciplinary involvement of specialists, covering the areas of art history, architecture and engineering, is required.

The HBIM practical cases reviewed in our study show successful HBIM applications. In addition, successful HBIM case studies can also be found in a review of practical cases by Ewart [28] from the year of 2008 to 2017, and in other studies [29-31]. All these studies are previous to our study. As HBIM practical cases show, the initial study of the historical contextualization of the building, the study of materials and analysis of construction processes are important. The importance of the methodology of information collection, standardization, construction techniques, the use of scanners, virtual reality and photogrammetry is reported in our study and has already been reported in previous reviews up to 2019 [31-38] and 2020 [39]. Studies focusing on linked open data (LOD) [40], digital documentation of heritage buildings [37] and performance assessment in HBIM [41] remain areas of interest.

\section{Conclusions}

In the maintenance of the heritage value of a historic building, respect for the past is required, but at the same time, buildings must be renewed for the future. Reconverting degraded or abandoned buildings into functional spaces is a positive strategy for preserving history. In this context, the HBIM methodology is relevant in several aspects, namely, collecting information using register documentation, 3D scanner and drone technologies, photogrammetry and stratigraphy procedures; modeling specific collections of parametric objects through the rigorous representation of geometric patterns or rules identifying form; and the generation of as-built models according to different constructive phases following a historical hierarchy.

The use of HBIM and its associated information is currently considered the preferential mode of work in the preservation of heritage buildings, as it supports collaboration and the easy management of relevant information. The recognition of construction processes and ancestral materials applied in each case, archived in a digital format and in an adequate hierarchical organization of the data, serves as a useful support for the analysis required in recovery or reconversion projects. The HBIM perspective is an aspect of permanent discovery and innovation, contributing positively to the preservation of the history of buildings.

Author Contributions: Conceptualization, A.Z.S., A.M.G. and A.S.-L.; investigation, A.Z.S., A.M.G., A.S.-L., P.Z. and C.G.-G.; methodology, A.Z.S., A.M.G., A.S.-L., P.Z. and C.G.-G., supervision, A.Z.S., A.M.G., A.S.-L., P.Z. and C.G.-G.; validation, A.Z.S., A.M.G., A.S.-L., P.Z and C.G.-G.; writing, original draft, A.Z.S., A.M.G., A.S.-L., P.Z. and C.G.-G. writing, review and editing, A.Z.S., A.M.G., A.S.-L., P.Z. and C.G.-G. All authors have read and agreed to the published version of the manuscript.

Funding: This research received no external funding.

Institutional Review Board Statement: Not applicable. 
Informed Consent Statement: Not applicable.

Data Availability Statement: Not applicable.

Acknowledgments: The authors wish to express their gratitude for the support from the Manufacturing Engineering Society (MES) and PATRIF work group (Industrial Heritage of Manufacturing work group of Manufacturing Engineering Society).

Conflicts of Interest: The authors declare no conflict of interest.

\section{References}

1. Sampaio, A.Z. BIM as a Computer-Aided Design methodology in Civil Engineering. Int. J. Softw. Eng. Its Appl. 2017, 10, 194-210. [CrossRef]

2. Quattrini, R.; Malinverni, E.S.; Clini, P.; Nespeca, R.; Orlietti, E. From TLS to HBIM. High quality semantically-aware 3D modeling of complex architecture. Int. Arch. Photogramm. Remote Sens. Spat. Inf. Sci. 2015. [CrossRef]

3. Murphy, M.; Mcgovern, E.; Pavia, S. Historic Building Information Modelling: Adding intelligence to laser and image based surveys of European classical architecture. ISPRS J. Photogramm. Remote Sens. 2013, 76, 89-102. [CrossRef]

4. Brumana, R.; Della Torre, S.; Previtali, M.; Barazzetti, L.; Cantini, L.; Oreni, D.; Banfi, F. Generative HBIM modelling to embody complexity (LOD, LOG, LOA, LOI): Surveying, preservation, site intervention, the Basilica di Collemaggio (L'Aquila). Appl. Geomat. 2018, 10, 545-567. [CrossRef]

5. Sampaio, A.Z.; Pinto, A.M.; Gomes, A.M. Historic Building Information Modelling (HBIM): Parametric modelling and documentation record. In Proceedings of the ENCORE 2020-Meeting on Conservation and Rehabilitation of Buildings, Lisbon, Portugal, 3-6 November 2020; pp. 815-826.

6. Osello, A.; Lucibello, G.; Morgagni, F. HBIM and Virtual Tools: A New Chance to Preserve Architectural Heritage. Buildings 2018, 8, 12. [CrossRef]

7. Bruno, N.; Roncella, R. HBIM for Conservation: A New Proposal for Information Modeling. Remote Sens. 2019, 11, 1751. [CrossRef]

8. Ali, M.; Ismail, K.M.; Hashim, K.S.; Suhaimi, S.; Mustafa, M.H. Historic building information modelling (HBIM) for Malaysian construction industry. Plan. Malays. J. 2018, 16. [CrossRef]

9. Pinto, A.M. The Design of Structures in BIM: Reconversion of Building of Patrimonial Value. Master's Thesis, University of Lisbon, Lisbon, Portugal, 2020.

10. Ramalho, M.M. Building Archeology and Surveying Methodologies Tradition Can Not Be What it Was. In Proceedings of the 3rd International Seminary ArcHC_3D, Lisbon, Portugal, 31 January 2011.

11. Cenani, S. A shape grammar study: Form generation with geometric Islamic patterns. In Proceedings of the 10th Generative Art Conference (GA), Milan, Italy, 12-14 December 2007; Available online: https:/ / www.generativeart.com/on/cic/papersGA2007/ 22.pdf (accessed on 10 February 2021).

12. Sanchez, A.; Gonzalez-Gaya, C.; Zulueta, P.; Sampaio, A.Z.; Torre, B. Academic proposal for heritage intervention in a BIM environment for a XIX century flour factory. Appl. Sci. 2019, 9, 4134. [CrossRef]

13. Carrera, M.A. Flour Factories in the Province of Valladolid; Caja de Ahorros Provincial de Valladolid: Valladolid, Spain, 1990.

14. Tolentino, M. The use of HBIM in the documentation, management and preservation of architectural heritage. In Proceedings of the 20th Congress of the Iberamerican Society of Digital Graphics, Buenos Aires, Argentina, 9-11 November 2016.

15. Genovez, S.C. Stratigraphic Analysis: A Contribution to the Restoration Project. Master's Thesis, Universidade de São Paulo, São Paulo, Brazil, 2012.

16. Murillo, J.I.; Agudo, M. The Romanesque in Santiago del Burgo (Zamora). Two projects, one church. Archaeol. Archit. 2008, 91-114. [CrossRef]

17. Osorio, J.L.; Torres, J.M. The stratigraphic analysis of the Arab bath of Churriana de la Vega (Granada): Synthesis of knowledge as the basis of the restoration project. Arqueol. Arquit. 2008. [CrossRef]

18. Ponte, M.; Bento, R.; Vaz, D. A multi-disciplinary approach to the seismic assessment of the National Palace of Sintra. Int. J. Archit. Herit. 2019. [CrossRef]

19. Cheng, H.-M.; Yang, W.-B.; Yen, Y.-N. BIM applied in historical building documentation and refurbishing. ISPRS Int. Arch. Photogramm. Remote Sens. Spat. Inf. Sci. 2015. [CrossRef]

20. Yang, X.; Lu, Y.-C.; Murtiyoso, A.; Koehl, M.; Grussenmeyer, P. HBIM Modeling from the Surface Mesh and Its Extended Capability of Knowledge Representation. ISPRS Int. J. Geo-Inf. 2019, 8, 301. [CrossRef]

21. Previtali, M.; Brumana, R.; Stanga, C.; Banfi, F. An Ontology-Based Representation of Vaulted System for HBIM. Appl. Sci. 2020, 10, 1377. [CrossRef]

22. Market of Romano Giulio, Pescherie di Levante. 2018. Available online: https://www.bimportale.com/la-traduzione-dellacomplessita-del-costruito-storico-nel-modello-hbim/ (accessed on 10 February 2021).

23. Baik, A. From point cloud to Jeddah Heritage BIM Nasif Historical House-Case study. Digit. Appl. Archaeol. Cult. Herit. 2017, 4, 1-18. [CrossRef] 
24. Santagati, C.; Papacharalambous, D.; Sanfilippo, G.; Bakirtzis, N.; Laurini, C.; Hermon, S. HBIM approach for the knowledge and documentation of the St. John the Theologian cathedral in Nicosia (Cyprus). J. Archaeol. Sci. Rep. 2021, 36, 102804. [CrossRef]

25. Church of Santiago de Peñalba. 2018. Available online: http://biblus.accasoftware.com/ptb/hbim-a-restauracao-da-iglesia-desantiago-de-penalba/ (accessed on 27 February 2021).

26. Murillo, J.I. Constructive sequence of the church of Santiago in Peñalba (Ponferrada, León). Renovations of a unitary building. Archaeol. Mediev. Territ. 2017. [CrossRef]

27. Van Eck, N.J.; Waltman, L. Software survey: VOSviewer, a computer program for bibliometric mapping. Scientometrics 2010, 84, 523-538. [CrossRef] [PubMed]

28. Ewart, I.J.; Zuecco, V. Heritage Building Information Modelling (HBIM): A Review of Published Case Studies. Adv. Inform. Comput. Civ. Constr. Eng. 2019, 35-41. [CrossRef]

29. Khodeir, L.M.; Aly, D.; Tarek, S. Integrating HBIM (Heritage Building Information Modeling) Tools in the Application of Sustainable Retrofitting of Heritage Buildings in Egypt. Procedia Environ. Sci. 2016, 34, 258-270. [CrossRef]

30. Pocobelli, D.P.; Boehm, J.; Bryan, P.; Still, J.; Grau-Bové, J. BIM for heritage science: A review. Herit. Sci. 2018, 6, 23-26. [CrossRef]

31. Woodward, A.; Heesom, D. Implementing HBIM on conservation heritage projects: Lessons from renovation case studies. Int. J. Build. Pathol. Adapt. 2019. [CrossRef]

32. García, E.S.; García-Valldecabres, J.; Blasco, M.J.V. The use of hbim models as a tool for dissemination and public use management of historical architecture: A review. Int. J. Sustain. Dev. Plan. 2018, 13, 96-107. [CrossRef]

33. Yang, X.; Grussenmeyer, P.; Koehl, M.; Macher, H.; Murtiyoso, A.; Landes, T. Review of built heritage modelling: Integration of HBIM and other information techniques. J. Cult. Herit. 2020, 46, 350-360. [CrossRef]

34. Santos, R.; Costa, A.A.; Silvestre, J.D.; Pyl, L. Informetric analysis and review of literature on the role of BIM in sustainable construction. Autom. Constr. 2019, 103, 221-234. [CrossRef]

35. Radanovic, M.; Khoshelham, K.; Fraser, C. Geometric accuracy and semantic richness in heritage BIM: A review. Digit. Appl. Archaeol. Cult. Herit. 2020, 19, e00166. [CrossRef]

36. Liu, Z.; Lu, Y.; Shen, M.; Peh, L.C. Transition from building information modeling (BIM) to integrated digital delivery (IDD) in sustainable building management: A knowledge discovery approach based review. J. Clean. Prod. 2020, 125223. [CrossRef]

37. Khalil, A.; Stravoravdis, S.; Backes, D. Categorisation of building data in the digital documentation of heritage buildings. Appl. Geomat. 2020, 29-54. [CrossRef]

38. Panteli, C.; Kylili, A.; Fokaides, P.A. Building information modelling applications in smart buildings: From design to commissioning and beyond a critical review. J. Clean. Prod. 2020, 265, 121766. [CrossRef]

39. Joblot, L.; Paviot, T.; Deneux, D.; Lamouri, S. Literature review of Building Information Modeling (BIM) intended for the purpose of renovation projects. IFAC-PapersOnLine 2017, 50, 10518-10525. [CrossRef]

40. Marden, J.; Li-Madeo, C.; Whysel, N.; Edelstein, J. Linked open data for cultural heritage: Evolution of an information technology. In Proceedings of the 31st ACM International Conference on Design of Communication, Greenville, NC, USA, 30 September-1 October 2013; pp. 107-112.

41. Bruno, S.; De Fino, M.; Fatiguso, F. Historic Building Information Modelling: Performance assessment for diagnosis-aided information modelling. Autom. Constr. 2018, 86, 256-276. [CrossRef] 